\title{
Film Content Analysis on FIAF Cataloguing Rules and CEN Metadata Standards
}

\author{
Rubén Domínguez-Delgado \\ University of Seville, Spain.rdd@us.es
}

\begin{abstract}
Cataloguing manuals published by the International Federation of Film Archives (FIAF) and the film metadata standards EN 15744 and EN 15907 have proven to be really useful for film archives in the process of film cataloguing. However, beyond the technical or formal aspects of films contemplated on these rules, there are some important aspects about the film content analysis which have not been taken into consideration.
\end{abstract}

We are showing with examples and analyzing all the references to the important task of content analysis on the historical evolution of these standards for film archives, discussing about the possibilities of adoption of more film content fields on them, what would suppose better possibilities of retrieval of film information by the users of film archives, adapting to their needs and to the new era.

\section{KEYWORDS}

film librarianship, film archives, film content analysis, film cataloguing, metadata, retrieval of film information

\section{INTRODUCTION}

Most theorists in archival and library and information sciences agree about the importance of content analysis in information systems for convenient retrieval of information by users. The UNESCO Recommendation for the Safeguarding and Preservation of Moving Images asked moving-image archives to provide the best access possible to their collections by users (UNESCO, 1980, 158).

However, two recently published studies showed that current film content analysis in film archives, unlike moving images content analysis in TV archives, has alarming shortcomings, and it is characterized by a heterogeneity of criteria and models and by the absence of a systematic and general application of specific content analysis methodologies that allow for the selective retrieval of moving images by users (DomínguezDelgado \& López-Hernández, 2016a and 2016b).

\section{OBJECTIVES AND METHODOLOGY}

Wondering about these deficiencies in film archives and knowing of the scientific hole about this topic, we decided to

$80^{\text {th }}$ Annual Meeting of the Association for Information Science \& Technology, Washington, DC | Oct. 27-Nov. 1, 2017

Copyright: Rubén Domínguez-Delgado \& María-Ángeles López-Hernández, 2017

\author{
María-Ángeles López Hernández \\ University of Seville, Spain. alhernan@us.es
}

do this research, focused on the attention that the main international institutions which are the reference point in cataloguing for film archives have historically paid to film content analysis on the standards they produce. These institutions are the International Federation of Film Archives (FIAF) and the European Committee for Standardization (CEN).

We have selected and review the most important standards edited by these two model institutions: 1979 FIAF Film cataloguing, 1980 FIAF Handbook for film archives, 1991 FIAF Cataloguing Rules for Film Archives, 2016 FIAF Moving Image Cataloguing Manual, as well as the two Cinematographic Work Standards (CWS) published by CEN: EN 15744 (2009) and EN 15907 (2010).

On them, we have paid attention to the cataloguing fields and recommendations linked to the film contents, leaving formal or technical aspects aside. Our main goal is to find out the depth of the moving image content analysis on these rules, discussing about how it affects the current possibilities of retrieval of information by users.

\section{RESULTS}

On 1979 Film Cataloguing, it was recommended that, just for the case of non-fiction films, "the content of each scene should be descripted, including times and places where actions take place". Besides, contents should be divided "in different categories, using descriptors which can be selected from a formal thesaurus" (FIAF, 1979, p. 51). However, FIAF left in each archive's hands the application or not of these recommendations, depending on their collections, needs, goals and resources.

On 1980 A Handbook for film archives, it was included on it the same recommendation about content description for nonfiction films than on 1979 rules. Besides, there were new recommendations, such as the inclusion, just for the case of newsreels and magazines, of "one descriptor per sequence", as well as the next indications: "the content description should be always, as a goal, a style which can be achieved" or "the film should be watched to make sure the description is precise, better than the accumulation of subjective information from secondary resources" (FIAF, 1980, p. 49).

Besides, it was recommended to include the thematic classification and, inside this area, the film genre and the classification of the film content, according to Dewey Decimal Classification. It was also recommended a controlled vocabulary if film archives want to index the topics of films (FIAF, 1989, p.55). 
On 1991 FIAF Cataloguing Rules for Film Archives there was not any content field on the first six obligatory cataloguing areas. Only on the optional "Notes area", there were some references to film content to be followed by film archives "depending on their resources": the field Nature, scope or artistic form of the item (FIAF, 1991, p. 107) - the relevant film genre -, the field Contents and the field Summary. On Contents, it could be included "a list of contents of each segment which composes a film consisting on different parts, like newsreels" (FIAF, 1991, p. 125).

The Summary which could be given by archivists "should be an accurate and objective description of the film's actual content, based on a viewing of the item". Despite its optionality, FIAF considered it important since it "is designed to assist the user in pre-selecting moving image materials for viewing, thus helping him/her to eliminate unwanted materials and to concentrate upon those items most useful for his/her purposes". It was also indicated that the summary should include "an introduction outlining the plot, subject, or nature of the moving image, preferably including genre(s), time period(s), and location(s) of the events depicted, if appropriate". Additionally, it was pointed that "if known, indicate the presence and nature of stock footage or excerpts from other moving image materials which are used" (FIAF, 1991, p. 126).

On the 2016 FIAF Moving Image Cataloguing Manual, FIAF has already recognized that "the archival moving image field has changed dramatically in recent years, with technological advances revolutionizing cataloguing, preservation, and access practices" (2016, p. 1). However, although the content description fields on these rules are not already inside optional Notes but inside two specific spaces - Content Description and Subject/Genre/Form terms -, it is just recommended these indications on the first of them:

"Write a concise, objective, non-critical summary of the content of the moving image Work and/or Variant. Content descriptions can be synopses, brief TV guidelike one sentence description, shotlists, etc. There can be more than one type of content description in the record (...) If acceptable summaries are already available in secondary sources, cataloguers may use these, instead of taking the time to prepare summaries of their own (...) A content description may also be a shotlist or listing of the contents of an aggregate Work/Variant." (FIAF, 2016, p. 126).

Besides, "the content description can be based on a viewing of the work - not necessarily, as recommended on 1980 FIAF standards and as theorists advise -, accompanying documentation, or secondary sources, but the source should be clearly noted". Finally, it is pointed that just for unedited works - not for non-fiction films, as recommended on 1979 standards and on the FIAF 2013 working draft previous to the current cataloguing rules (FIAF, 2013, p. 33) -, and "where time and resources permit, each scene should be summarized". However, it is at least pointed that "if there are shots of particular significance or interest - of, for example, prominent people or places - these should be recorded - example on Figure 1. Otherwise a general description of scenes and sequences will suffice" (2016, p. 127).

Clips:
00:00:06:02
Duración:
00:02:55:10
Titulo:
Escenas familiares en Ulia
Descripción:
Imágenes de Lola y Antonio con su padre en las campas de Ulia.

Figure 1. Special shots' content description at Filmoteca Vasca (Spain).

On the other hand, on the field Subject/Genre/Form terms, it is recommended:

"Provide access to the Work by means of subjects (or subject identifiers) that describe the content of the Work (i.e., what the Work is about) - but places, times or names of people or entities are not considered to be recorded, as recommended by theorists in the field of moving image librarianship (Caldera Serrano and Sánchez Jiménez, 2009) -. Use an existing data value standard such as Library of Congress Subject Headings (LCSH). Alternatively, or additionally, use standards such as Universal Decimal Classification $(U D C)$, Dewey Decimal Classification (DDC) - the only one recommended on the previous 1991 FIAF rules -, or equivalent (...) In addition, access to the Work can be provided by means of genre(s) and/or form(s) (or identifiers) of which the Work is an example" (FIAF, 2016, p. 44).

About metadata standards for cinematographic works (CWS) published by CEN, the first one, EN 15744 (2009), only paid attention to film content on the field Genre (Flores Riesco, 2009 , p. 31), recommending on it the use of descriptors taken from a controlled vocabulary. Surprisingly, this standard does not have into consideration even the general summary nor any kind of indexing.

Finally, on the standard EN 15907 (2010) there are four references linked to film content analysis. Inside the space Elements, there are two content fields: content description and subject fields, being indicated about the last ones that "controlled and uncontrolled terms may be used together, but not within a single set of subject terms" (CEN, 2010). Inside Common element types, we find the fields "region", for places, and "timespan", for times represented in films.

Although it seems that there is a greater concern about film content description on the last CEN metadata standards than 
on the one in 2009, as well as on the last FIAF cataloguing manual, since they consider places and times in the description of film content - no other standard did it -, there is a large lack of information or examples about each one of these four fields.

Due to these deficiencies on film metadata and cataloguing standards, some film archives have created some initiatives to improve the possibilities of access to film collections by their users, like the project I-Media-Cities (IMediaCities.eu, 2016-2019).

\section{CONCLUSIONS}

In spite of the considerable work of FIAF and CEN during last years, if they do not pay more attention to film content on their recommendations for film archives, asking them to analyze much more deeply and systematically the content of films to let their users a selective and exhaustive retrieval of film information, according to the new digital and technological era, as many TV archives already did, users, researchers and citizens in general can lose their interest for this important patrimony as a resource of information and film archives could lose their visibility and useful for Society and Governments. In fact, it seems to be already happening in many countries like Spain, whose main national archive's budget has been reduced the $60 \%$ between 2010 and 2014 (Domínguez-Delgado and López-Hernández, 2016c, p. 14).

\section{ACKNOWLEDGMENTS}

This research has been financed by the VI Plan Propio de Investigación de la Universidad de Sevilla.

\section{REFERENCES}

Bowser, E. \& Kuiper, J (1980). A Handbook for Film Archives. Bruselas: FIAF.

Caldera-Serrano, J. \& Sánchez-Jiménez, R. "Recuperación de Secuencias de Información Audiovisual con Rdf y Smil". In $E l$ Profesional de la Información, vol. 18, n. 3, 2009, pp. 291299.
European Committee of Standardization (CEN) (2010). "EN 15907. Film identification-Enhancing interoperability of metadata - Element sets and structures". In Filmstandards.org. Retrieved May 15, 2017 from http://filmstandards.org/fsc/index.php/EN_15907

Domínguez-Delgado, R. \& López-Hernández, M.A. (2016a). "Film content analysis at six major Spanish film libraries". In El Profesional de la Información, v. 25, n. 5, pp. 787-794. eISSN: 1699-2407.

Domínguez-Delgado, R. \& López-Hernández, M.A. (2016b). “The Retrieval of Moving Images at Spanish Film Archives: The Oversight of Content Analysis". In Proceedings of the Association for Information Science and Technology, volumen 53, issue 1, 2016, pp. 1-4. Online ISSN 2373-9231.

Domínguez-Delgado, R. \& López-Hernández, M.A. (2016c). "Film Librarianship: historical contextual framework". In Documentación de las Ciencias de la Información, 39, pp. 13-49.

Imediacities.eu (2016-2019). I-Media-Cities. Retrieved June 2, 2017 from https://imediacities.eu/

International Federation of Film Archives (FIAF) (1979). In Film Cataloguing. New York: Burt Franklin \& Co., 1979.

International Federation of Film Archives (FIAF) (1991). FIAF Cataloguing Rules for Film Archives. München, London, New York, Paris: KG Saur.

International Federation of Film Archives (FIAF) (2013). Working draft of the FIAF Moving Image Cataloguing Manual, February. Retrieved May 9, 2017 from http://www.filmstandards.org/fiaf/wiki/doku.php

International Federation of Film Archives (FIAF) (2016). FIAF Moving Image Cataloguing Manual. FIAF.

Flores Riesco, C. (2011). Metadatos para Documentos Audiovisuales. La Normalización en Europa. Master Thesis directed by Carmen Caro Castro. Salamanca: University of Salamanca.

Unesco (1980). "Recommendation for the Safeguarding and Preservation of Moving Images", Records of the General Conference, $21^{\text {st }}$ session, Belgrade, 23 September to 28 October, Vol. 1, Resolutions, pp. 156-161. 